\title{
ESTUDO DA RELAÇÃO ENTRE AS PROTEÍNAS NPM1 E NCL E AS DIFERENTES ISOFORMAS DE S6KS
}

\section{Fernando Riback Silva, Isadora Carolina Betim Pavan, Ana Paula Morelli, Fernando Moreira Simabuco}

\begin{abstract}
Resumo
A via de sinalização da mTOR vem sendo relacionada a desordens metabólicas em humanos, como a obesidade, diabetes e vários tipos de câncer. As proteínas S6K1 e S6K2 têm mostrado importante papel na sinalização da mTOR, funcionando como efetoras dessa via. Em estudos anteriores, foram identificadas proteínas com elevado score de interação com as S6Ks, dentre estas estão a Nucleofosmina1 (NPM1) e a Nucleolina (NCL), proteinas envolvidas na biogênese de ribossomos, proliferação celular e regulação de supressores tumorais. Portanto, esse estudo investiga a possivel interação entre as proteínas NPM1 e NCL com as diferentes isoformas de S6Ks, a fim de entender melhor o envolvimento da via mTOR/S6Ks com desordens metabólicas, com enfoque no câncer.
\end{abstract}

\section{Palavras-chave:}

Nucleofosmina, Nucleolina, Câncer.

\section{Introdução}

A via da mTOR (mammalian Target Of Rapamycin) está envolvida em diversas desordens metabólicas, como câncer, obesidade e diabetes. O principal papel da proteína mTOR é servir como um sensor da disponibilidade de nutrientes, já que mTOR é estimulada por altas quantidades de aminoácidos, ATP e insulina ${ }^{1}$. A via da mTOR apresenta como sua principal efetora, as proteínas S6Ks (S6 Kinases) ${ }^{2}$. Existem dois genes conhecidos das S6Ks que codificam duas proteínas diferentes, chamadas p70-S6K1 e p54-S6K2, respectivamente. Estudos realizados pelo nosso grupo revelam que, apesar da grande homologia entre essas proteínas, existem diferenças significativas nas suas funções, na participação em processos celulares, em seus parceiros de interação ${ }^{3}$, bem como diferenças na sensibilidade a quimioterápicos, como o docetaxel ${ }^{4}$. As proteínas Nucleofosmina1 (NPM1) e Nucleolina (NCL) participam da biogênese de ribossomos, proliferação celular e regulação de supressores tumorais, de forma que vários estudos demonstram o envolvimento dessas proteínas em diversos tipos de câncer ${ }^{5}$. Um estudo proteômico ${ }^{3}$ demonstrou que NPM1 e NCL apresentam um elevado score de interação com as S6Ks. Sendo assim, o objetivo desse estudo é investigar a interação das proteínas NCL e NPM1 com a diferentes isoformas de S6Ks e, dessa forma, contribuir para o melhor entendimento da via mTOR/S6K em distúrbios metabólicos, com enfoque no câncer.

\section{Resultados e Discussão}

A realização de knockdown de NPM1 foi realizada em células tumorigênicas e não tumorigênicas nos quais obtivemos resultados distintos com relação aos níveis de fosforilação de S6K1 e S6 (Figura 1). Foram realizados ensaios funcionais utilizando o knockdown de NPM1 sendo que os resultados mostraram menor viabilidade celular, menor migração e menor proliferação em células com knockdown. Portanto nossos dados sugerem que NCL e NPM1 apresentam uma relação com as S6Ks sendo esses achados diferentes entre células tumorigênicas e não tumorigênicas. Sabe-se que essas duas proteínas de interesse estão diretamente ligadas com processos de proliferação celular, biogênese de ribossomos e síntese proteica, portanto, o presente estudo pode elucidar novos mecanismos de ação das S6Ks nesses importantes processos biológicos.
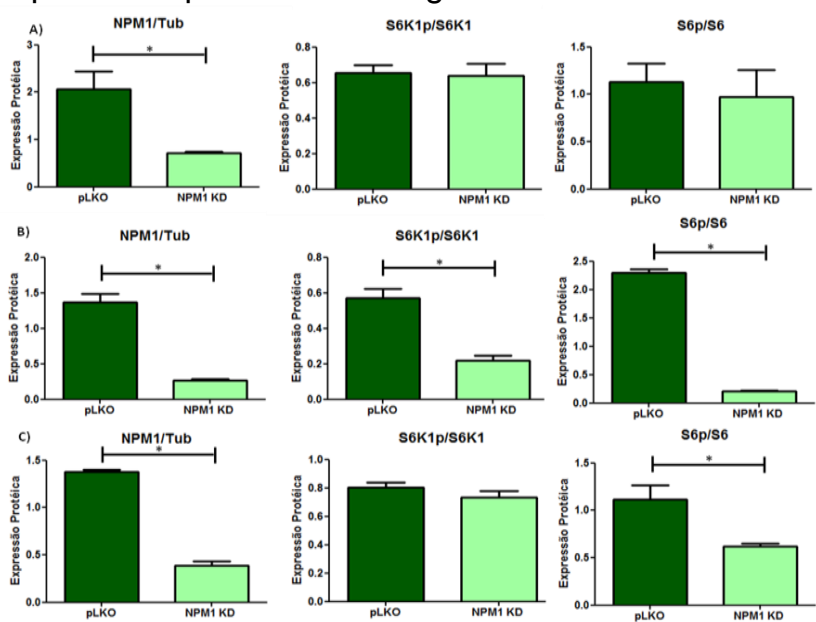

Figura 1. Knockdown de NPM1 em células HEK293, PC3 e DU145 diminui fosforilação de S6Ks. A)-C) Gráficos mostrando a diferença estatística na expressão de NPM1 e fosforilação de S6K1 e S6 em HEK293, PC3 e DU145 respectivamente. Usado teste t de Student com $n=3$.* $p<0,05$.

\section{Conclusões}

Os resultados com o knockdown indicam que a relação de NPM1 com as S6Ks é dependente do tipo celular, evidenciando uma interação diferenciada dessa proteína em linhagens celulares cancerígenas (PC3 e DU145). Além disso os ensaios funcionais sugerem que 0 knockdown de NPM1 pode ter efeitos benéficos em células tumorigenicas quando comparadas ao controle.

\section{PIBIC-CNPQ e FAPESP}

\section{Agradecimentos}

\footnotetext{
${ }^{1}$ Magnuson B, et al. Biochem J.;441(1):1-21. 2012

${ }^{2}$ Dann, S. G.; Selvaraj, A.; Thomas, G. Trends Mol. Med.2007; 13: 252-259.

${ }^{3}$ Pavan, I.C, et al. Proteomics. 2016 Oct;16(20):2650-2666.

${ }^{4}$ Amaral C.L, et AL. BMC Cancer. 2016 Aug 5;16:602.

${ }^{5}$ Nalabothula, N, et al. Mol Cell Pharmacol. 2010; 2: 179-189.
} 